\title{
10
}

\section{YOUR FAKE NEWS, OUR FACTS}

\author{
Identity-based motivation shapes \\ what we believe, share, and accept
}

\author{
Daphna Oyserman and Andrew Dawson
}

\section{Introduction}

On June 23, 2016, British voters went to the polls, or rather, seven in ten British voters went to the polls; the others refrained (The Guardian, 2016). The less than full turnout was surprising because what was at stake was whether or not Britain (England, Northern Ireland, Scotland, and Wales) would remain part of the European Union (EU) as they had been since 1973. The EU was built on the assumption that members were safer, stronger, and freer together - their countries less likely to face war; their economies more prosperous; their citizens more able to choose their own path. A British generation had grown up with London as an EU financial center (Brush \& Weber, 2019), with EU research funds flowing into British universities (UK Research and Innovation, 2019) and British products flowing seamlessly through the EU, Britain's largest trading partner, dwarfing trade with its next three largest trading partners combined (McCrae, 2018). This generation had grown up assuming that they could flow too - be educated, get jobs, raise families anywhere in the EU. As noted by the Stay campaign website (www.strongerin.co.uk/), voting to leave would undermine all of that. ${ }^{1}$ It would leave Britain alone in a connected world and, by creating borders with Ireland, an EU member, would undermine a central element of the 1999 Good Friday peace accord with Northern Ireland that ended a long and bloody history of strife. Not only that, but the leave campaign provided no plan for how borders, trade, and already signed commitments would be handled if Britain exited the EU (Cooper, 2016).

Yet, the "exit" vote won at 51.9\%. Not only that, but 18-to-24-year-olds, those with the most time at stake in the future, overwhelmingly voted "stay" but were also much less likely to vote at all than pensioners who came out in force and voted "exit" overwhelmingly (The Guardian, 2016). The same was true for 
Northern Ireland, where only six in ten voters went to the polls (the majority of those who did vote, voted stay (BBC, 2016). Why did so many young voters and so many Northern Irish voters fail to vote on a referendum on what their future would be? Why might pensioners set Britain up to renege on the Good Friday agreement and undermine their financial certainty? One possibility is that this happened because people did not use the information just described in making their choice and instead reframed their choice (attribute substitution, Kahneman \& Frederick, 2002). Instead of addressing the question of how leaving would address the problems in British society or the question of how it would provide alternatives to the benefits of being part of the EU, people addressed a different question. Rather than attempting to synthesize complex information regarding which choice would be better for Britain's economic and security future, people asked which choice felt like an "us" thing to do. If they could not decide, they stayed at home (Douthat, 2015; Massie, 2015).

How did this reframing occur? That is our focus in the current chapter. We suggest that people shifted from a complicated-to-answer information-based question to a simple-to-answer identity-based question. An information-based approach would require considering the relevance of large quantities of estimated data on costs (how much Britain paid into the EU), benefits (what Britain received from the EU), and alternatives (changes required to maintain trade, peace, and secure borders). To do so, for example, they would have to read reports to figure out if being in the EU lengthened wait times at the National Health Service (Giuntella, Nicodemo, \& Vargas-Silva, 2015). They would have to read reports to figure out if unwanted people living and working in Britain were due more to being in the EU or too lax British policies on employment, on tracking people who overstayed visas, and of not having national identity cards (Blinder \& Markaki, 2018; Goodwin, 2015). In contrast, an identity-based approach required simply that people ask themselves what "stay" or "leave" implied for who they were and might become - whether "stay" or "leave" felt more like an "us" thing to do.

In the current chapter, we focus on persuasive attempts to shift people from information-based to identity-based reasoning. To do so, we distinguish between disinformation and information. Disinformation is content shared to produce a particular judgment or course of action in message recipients, irrespective of the veracity, or bias of what is shared. In contrast, information is content shared to inform message recipients, what is shared is assumed to be true. As we detail, the persuasive power of a disinformer's call to action comes from weaponizing people's cultural expertise to efficiently channel them from information-based to identity-based processing.

We outline the steps in making this happen - creating the appearance of a culturally relevant "legitimate" question, framing the issue as an identity-based rather than an information-based concern, presenting a clear identity-based choice, and framing alternative choices as identity threatening. At step 1, disinformation campaigns use people's cultural expertise to reframe topics as questions, taking 
what would otherwise be considered an "illegitimate" question, because the answer goes without saying, and reframing it as a "legitimate" question - one in which the answer does not go without saying. At step 2, disinformation campaigns capitalize on people's cultural expertise so that the topic is framed in culturally fluent terms by using culturally recognizable icons, phrasing, embodied, and sensory cues. Having set the stage, disinformation campaigns frame a specific course of action as identity-relevant (what "we" do) and for good measure, suggest that failure to take the identity-relevant action threatens the identity itself - in the case of leaving the EU, that staying would result in a loss of British identity. Thus, as we outline in this chapter, there is more to the story than simply the lack of information or the presence of misinformation. It is how persuasive messages channel people to use their identities to make sense of what information implies for action that matters.

We use Britain and the 2016 British referendum on whether to stay in or secede from the EU as our concretizing example to frame our discussion of these three steps. The referendum was nicknamed Brexit, a mashup of the words "British" and "exit." This nickname helped frame the question of whether to stay or secede as being about exiting the EU. Alternative nicknames, for example, Brit-in, a mashup of the words "Britain" and "in" would have shifted framing to be about staying in the EU. In the next section, we operationalize what we mean by cultural expertise and why it matters for reasoning.

\section{Cultural expertise, cultural fluency, and cultural disfluency}

From an ecological perspective, group living is a survival necessity and human culture is essential to adapting to group living (Boyd \& Richerson, 2005; Cohen, 2001; Haidle et al., 2015; Kurzban \& Neuberg, 2005). Group living requires that people develop "social tuning" (sensitivity to others' perspectives) and "selfregulation" (the ability to control the focus of one's attention) skill (Chiu et al., 2015; Oyserman, 2011, 2017; Shteynberg, 2015). These culturally necessary skills are the basis of cultural practices evolved to create "good enough" solutions to the survival problems of coordinating, fitting in, and sharing. These solutions are "good enough", rather than optimal, but, once developed, they become "sticky" by virtue of being the way "we" do things - "our" structures, practices, norms, and values (Cohen, 2001; Oyserman, 2015a). They permeate all aspects of behavior, constrain and enable perception and reasoning, and provide a shared blueprint or outline for meaning-making across a variety of situations (Chiu, et al., 2010; Nisbett \& Norenzayan, 2002; Oyserman, 2017; Shweder \& LeVine, 1984; Triandis, 2007).

In this way, culture is in part a set of associative knowledge networks, tacit operating codes, or meaning-making frameworks through which people make sense of their world, understand what they want, and how they go about getting it. These culture-rooted associative knowledge networks provide mental models, affording people the cultural expertise to predict how situations will 
likely unfold. Each of a culture's "good enough" solutions entails a knowledge network including the content, procedures, and goals related to its overarching theme - individualism, collectivism, and honor. The same is the case for each of a culture's practices. Each practice entails knowledge networks, including specific, often implicit, knowledge about how things work - what brides wear, what breakfast entails, and so on. Immediate contexts make some subset of available cultural knowledge networks accessible in the moment.

\section{Cultural mindsets shape accessible mental procedures}

People use the subset of their available culture-based knowledge that is accessible at the moment of judgment to make an automatic prediction about what will happen next. People use the mental procedure associated with an accessible cultural mindset. For example, after an individualistic mindset is primed, people are better at quickly naming a distinct object in a visual array (Oyserman, Sorensen, Reber, \& Chen, 2009, Study 3). This response suggests that they are using a pull-apart-and-separate procedure. In contrast, after a collectivistic mindset is primed, people are better at recalling where objects were in a visual array (Oyserman et al., 2009, Studies 1,2) and have more trouble ignoring extraneous visual (Oyserman et al., 2009, Studies 4, 5) or auditory (Oyserman et al., 2009, Studies 6, 7) information. This response suggests that they are using a connect-and-relate procedure. Other studies support these procedure-based predictions of an accessible collectivistic mindset (e.g., Mourey, Oyserman, \& Yoon, 2013; Oyserman et al., 2009). After this happens, people are willing to pay more to complete a set (Mourey et al., 2013, Study 1b). They are willing to accept previously undesired options if a set cannot be completed (Mourey et al., 2013, Studies 2 to 4). They have more difficulty finding the best match and ignoring other plausible but not as good matches in a standardized antonym and analogies task (Oyserman, et al., 2009, Study 8). People from different countries (the United States, Norway, Hong Kong, Korea) and different racial-ethnic groups (e.g., Latino, African American, Asian, or Asian American) shifted to using or not using a collectivistic mindset, depending on momentary cues. Across experiments, the mental procedure people used depended on the cultural mindset accessible in the moment. Anything that makes people's group-based identities (e.g., being British, being rural, being patriotic) salient at the moment should trigger their use of a collectivistic mindset (Oyserman, 2007). Once a collectivistic mindset is triggered, people are more willing to focus on how things connect and that can make it harder to see flaws in logic (Oyserman, 2019a).

\section{Cultural knowledge shapes what is fluent and disfluent and hence reasoning style}

Cultural knowledge sets up implicit expectations as to how things will unfold. It is easier for people to make sense of a situation that unfolds as they expect that it 
will and more difficult for them to make sense of a situation if the way it unfolds violates their implicit expectations. A classic example comes from Bruner and Postman (1949). They showed that American college students were slower to recognize shapes when they saw shapes (hearts, diamonds, clubs, spades) in colors that mismatched (e.g., a red spade) their culture-based knowledge about the color of these shapes on playing cards (they are supposed to be black). Students in this study applied their culture-based knowledge automatically. They did so even though the experimenters never said that the task was a playing card shape task and never told them that they should use their knowledge of the colors of shapes on playing cards. They applied their knowledge automatically. As a result, people had trouble discerning shape when the shape was a club but the color was red. People were particularly likely to apply their culture-based knowledge on the first card they saw and seemed to continue to use their culture-based knowledge unless multiple trials showed it was irrelevant. Culture, of course, is dynamic, and that experiment will only replicate among current American college students if playing cards are as common a pursuit now as it seems to have been when the experiment was originally conducted in the 1940s.

Cultural knowledge not only makes it easier to process culturally fluent information, but it also helps people know when something is not right, triggering a shift from associative, gut-based reasoning to systematic, rule-based reasoning when the unexpected occurs (Oyserman, 2011). As an example, consider four experiments conducted by Mourey, Lam, and Oyserman (2015). In each experiment, the cultural cue (independent variable) was being exposed to a culturally fluent (matched cultural expectation) or culturally disfluent (mismatched cultural expectation) situation or product. The first experiment involved having or not having the color pink as a border on Valentine's Day or after Valentine's Day, the second and third involved first rating the quality of photographs of weddings, the fourth involved first choosing among formats of an obituary for a family and then engaging in the cognitive task. The prediction was that cultural expertise would make the match easier to process than the mismatch and that this cultural expertise-driven processing difficulty would trigger a shift to systematic reasoning.

The effect on reasoning (dependent variable) was assessed with a cognitive task that was specifically devised to have both a gut-based and a rule-based answer. Though gut-based responses are not always wrong, they lead people astray in situations in which applying a processing rule does not come naturally but is the correct way to proceed. Here is an example from the original task (taken from Frederick, 2005): “A fishing rod and fishing bait cost \$1.1 in total. The fishing rod costs $\$ 1.0$ more than the bait. How much does the bait cost?" The gut-based but incorrect response is $\$ .10$ based on the gist focus on the " $\$ 1.0$ " piece of information resulting in simply subtracting $\$ 1.0$ from $\$ 1.1$ ( $\$ 1.1-\$ 1.0=$ $\$ .10)$. The rule-based and correct response is $\$ .05$ based on the rule-based focus on the " $\$ 1.0$ more" as a piece of information resulting in the equation: $\$ 1.1=n+$ $(n+\$ 1.0)$. People give the $\$ .10$ gut-based or $\$ .05$ rule-based response, only a 
few people give answers that cannot be coded as gut or rule-based (answers other than $\$ .10$ or $\$ 0.05)$.

The first experiment took place in Ann Arbor, Michigan (United States), and in Hong Kong, S.A.R. China. In each location, people were randomly assigned to one of four groups - groups varied as to the day (Valentine's Day or a week later) they were approached and the screen border color (pink, not pink) they saw. One group (cultural fluency group) did the task on Valentine's Day and worked on a screen that displayed a pink-colored border. The other three groups were control groups. They did the task on Valentine's Day but without a pinkcolored border, or a week after Valentine's Day with or without the pink-colored border. People who were randomly assigned to the cultural fluency group saw a pink border on Valentine's Day (the "right" color at the "right" time). This match to culture-based expectation preserved "gut"-based reasoning even when rule-based reasoning was needed. Indeed, people in the cultural fluency group were more likely to give the wrong answer than people in the other three groups (who did not differ). The rule was not hard to apply, it just required that people notice that it should be applied. The time people took to respond did not differ for those who used a rule compared to those who used their gut.

This finding - that even in situations calling for rule-based, systematic reasoning, people stuck to associative gut-based reasoning after receiving culturally fluent cues, was replicated in three follow-up experiments. Tellingly, in these experiments, effects were found even though exposure to the cultural cue that triggered cultural fluency and disfluency was separate from the subsequent reasoning task. In two experiments, cultural expertise about weddings was triggered. In these wedding studies, half of the participants were randomly assigned to rate eight culturally fluent wedding photographs and the other half were randomly assigned to rate eight culturally disfluent photographs. In the culturally fluent photographs, the bride was in white, the groom in black, their tiered wedding cake had white fondant icing, and their wedding party had bridesmaids and groomsmen. In the culturally disfluent photographs, the bridal dress included some green and purple, the groom's tuxedo also had some purple, their tiered wedding cake was decorated with colorful cogs, and there was no wedding party. In the final experiment, cultural expertise about funerals and mourning was triggered. In this obituary study, half of the participants were randomly assigned to a culturally fluent obituary set and the other half to a culturally disfluent obituary set. In the culturally fluent condition, they saw two versions of the same sad in tone, praising the deceased, obituary. In the culturally disfluent condition, they saw two versions of the same not sad in tone, not praising the deceased obituary. The researchers found the not sad, not praising obituary and created a parallel sad, praising obituary. Thus, "had no hobbies . . . will not be missed" in the original was edited to "had numerous hobbies . . . will be missed". The researchers made two versions of each obituary by rearranging paragraph order.

Across experiments, the people who were randomly assigned to the culturally fluent condition were more likely to use gut-based reasoning than those 
randomly assigned to the cultural disfluent condition. As these experiments demonstrate, experiences of cultural fluency and of cultural disfluency are the result of the interface between what observers' cultural expertise leads them to (implicitly) expect, what they actually observe, and the meaning they draw from their ensuing metacognitive experiences of ease or difficulty (Oyserman, 2011, 2017). What makes for a metacognitive experience of ease or difficulty is not the observation itself but the match or mismatch between observation and culture-based expectation. Experiencing match or mismatch requires having the cultural expertise to know (implicitly) what to expect. These expectations are rooted in one's culture - what one has learned explicitly or picked up implicitly through observation and socialization practices. When messages appear in culturally fluent terms, people may be more susceptible to disinformation simply because the message does not trigger a shift to systematic reasoning (Oyserman, 2019a).

\section{Cultural expertise and persuasive messages}

Prior research on cultural fluency and disfluency has not directly assessed the effects of cultural expertise on the people's processing of persuasive messages (for a review, Oyserman \& Yan, 2019). The reasoning strategy people use matters for which kind of message people find persuasive (Petty \& Cacioppo, 1981, 1984). If they are using an associative reasoning approach, they are less likely to notice differences in message quality than if they are using a systematic reasoning approach. Messages that use some mix of the images, phrasing, sounds, and content people tacitly expect are more culturally fluent. In this section, we consider how a message's cultural fluency might matter.

Recall that people are less likely to use systematic reasoning in culturally fluent situations. We infer from this that people may be less likely to reason systematically when they are confronted with culturally fluent persuasion attempts. Because they are not reasoning systematically, the quality of the persuasive argument may not matter as much. As a result of not paying attention to message quality, people may fail to distinguish information from misinformation messages meant to convey facts as known at the time, from factually incorrect or biased information. They may fail to distinguish between informational messages meant to inform choice and judgment, and disinformational messages meant to yield a particular course of action. For a message to be culturally fluent, a message needs to contain some mix of the images, phrasing, and content that people tacitly expect to see or hear in a situation.

As we articulate next, cultural fluency activates identity-based, rather than information-based, reasoning. When people are using information-based reasoning, they have access to both associative and systematic strategies. In contrast, when they are using identity-based reasoning, their access to systematic reasoning strategies is effectively blocked. We apply the logic of communication, described next, to explain why. 


\section{The logic of communication}

Following conventions of language use, people typically assume that message sharers have a goal of informing (Grice's maxims of communication or "logic of communication", Schwarz, 2014). That is, people assume that message sharers share content they believe to be factually true, unbiased, and potentially useful in informing judgment and decision making, even if sometimes message sharers get it wrong and, unbeknownst to themselves, misinform - share factually untrue or biased content. According to these conventions of language use, unless they have reason to be suspicious, people start with the assumption that communicators are attempting to be informative - to clearly tell them something that is relevant, something that their audience does not already know (Schwarz, 2014).

\section{The logic of communication and communicative intent}

The logic of communication serves people well when sender and receiver share a mutual goal of informing. Because their reasoning is shaped by the logic of communication, people make (often implicit) assumptions about information from how it is communicated (Gilbert, 1991; Gilbert, Krull, \& Malone, 1990; Schwarz, Strack, Hilton, \& Naderer, 1991; Schwarz, 2014; Schwarz \& Sudman, 2012; Sudman, Bradburn, \& Schwarz, 1996). They do so whether or not the communicator intended them to make these inferences and often without awareness of the source of their inference (Schwarz et al., 1991).

The logic of communication, however, can also shield the intentions of those message senders who do not have a goal of informing judgment and choice but instead have a goal of shaping judgment and producing a particular outcome (a judgment, a choice). Although message veracity and bias are relevant when message senders have a goal of informing, they are irrelevant when message senders have a goal of shaping judgment and producing a particular choice. As we noted in our opening paragraphs, we use the term "disinformation" to describe this latter form of message content shared by senders who do not have the intent to inform but the intent to shape recipient judgment and decision making independently of the probative content of the messages they send. Veracity and bias are irrelevant to disinformation messaging, it does not matter if the content is true or unbiased; it only matters if the intended response is produced (Weedon, Nuland, \& Stamos, 2017). What we are proposing is that people are particularly unlikely to notice disinformation if it is presented in a culturally fluent way because, in these situations, they are less likely to feel suspicious, notice something is off, and shift to systematic reasoning.

\section{The logic of communication and "legitimate" (versus "illegitimate") questions}

Because people make assumptions based on how information is communicated, communicators can raise doubt by simply asking a question. Following the logic 
of communication, question recipients typically assume cooperative intent. Regarding questions, cooperative intent implies that the communicator is posing a question because more than one option is possible. Having more than one possible answer is what makes a question legitimate. If there is only one possible answer, the question is not a legitimate one. But the possibility that the question is not legitimate is typically overlooked when people assume cooperative intent. That is why asking "who is buried in Grant's tomb?" (a question that includes its answer, Grant) is puzzling; if this is a legitimate question then that means that there is more than one possible answer option. That implies that Grant is not buried in Grant's tomb, that what seems to be the only possible answer (General Grant) is not. When the goal is not to inform but to disinform - to change judgment rather than to inform it, then raising a question can be a first step in changing judgment. Having been asked "who is buried in Grant's tomb?" people often respond by saying "I don't know, who?" having ruled out that it is Grant. But of course, this is not a legitimate question - Grant is buried in Grant's tomb. We propose that such illegitimate questions, ones not based on lack of a single answer, have the intention of sowing doubt and leading people to be open to being told any possible alternative.

In 2016, the question "should Britain exit the EU?" was not, at least initially, a clearly legitimate question. After all, if whether to leave the EU could be considered a legitimate question, it would imply that what was assumed to be true might not be so, that maybe being in the EU is a problem, otherwise, why ask the question? By getting the question on the ballot, the secession campaign succeeded in making the question seem as if it might be legitimate. Beyond getting the question on the ballot, the exit campaign could have used informational or disinformation messaging, as of course, could the stay campaign. In the next section, we outline what identity-based motivation is. Then we use identity-based motivation to explain the appeal of disinformation campaigns, using examples from the Brexit campaign (we looked for but did not find examples in the Stay campaign).

\section{Identity-based motivation}

\section{Dynamic construction, interpretation of experience, and action readiness}

Identity-based motivation (IBM) theory is a situated cognition theory of selfregulation that predicts that people prefer to make sense of situations and act in ways that feel congruent with their important social and personal identities (Oyserman, 2007, 2009, 2015b). Social identities are identities linked to group membership - being patriotic, nationalistic, British, a Londoner, a European, male, a parent, a taxpayer. These identities may be linked to a variety of content and in this way, overlap with personal identities - as fiscally prudent, proud, loyal. Social identities may reference both semantic content (what we value, our beliefs) and sensory content - what we look like, what we sound like, the tastes 
we like. People have many past, current, and future possible social and personal identities available to them in memory and these identities have no preset organizational structure (Oyserman, Elmore, \& Smith, 2012). Instead, people are affected by the particular identities that are accessible ("on their mind") at the moment of judgment, if these identities feel relevant to the task at hand.

\section{Dynamic construction}

To paraphrase William James (1890), thinking (about the self) is for doing. Because doing requires sensitivity to the affordances and constraints in the situation, which identities come to mind, and what these "on-the-mind" identities seem to mean, is sensitively attuned to momentary and chronic features of context (for a review, Oyserman et al., 2012). People not only pull from memory what an identity means, they also infer from context what an identity must mean given features of the immediate situation. In that sense, identities are dynamically constructed in the moment - the seemingly same identity may imply different actions in different contexts. Thus, in the moment, being British may be part of being European - when traveling without need of visas, but it could also be in contrast to being European - when people from other countries register their children in your local school. That people are sensitive to the implications of their immediate situation is a design feature, not a design flaw. Sensitivity to social context allows people to make inferences about what people like themselves likely do, which strategies work for them, and what inferences to draw when they progress smoothly as well as when they run into difficulties (Oyserman et al., 2017).

Using the logic that we outlined in the section on the evolution of culture, messages from in-groups should feel more credible - in-group members share values and are less likely to be harmful than out-group members. From an evolutionary perspective, being able to recognize who is in the in-group is critical. The in-group is safe, can be approached. The in-group is unlikely to deceive or pose a threat, reducing the need to be wary, suspicious, and guarded (Brewer, 1979; Platow, Foddy, Yamagishi, Lim, \& Chow, 2012). With the in-group, one's guard can be let down, but how can one tell who is providing the message? The senses can be a cue - people like "me" sound a certain way, use certain turns of phrase, have certain accents, and people like me "look" a certain way, wear certain styles, focus on certain iconic images, people like "me" share tastes, values, and desires. Thus, in-group messages are more likely to "ring true" and to "sound right"; they are more likely to feel familiar and be culturally fluent.

\section{Procedural readiness}

Sense-making or "procedural readiness" is the readiness to make sense of new situations in the ways afforded by the cued identities. For example, when collectivistic "we" social identities are cued, people are more likely to use connecting and relating mental procedures, whereas when individualistic "I" personal 
identities are cued, people are more likely to use separating and distinguishing mental procedures (Oyserman, 2007). This implies that if disinformation campaign message content includes social identities, the campaign message carries a trigger to think in terms of connections and associations rather than to focus on a main point. We show examples of this process in the section labeled Disinformation Campaigns and Identity-based Motivation.

\section{Action readiness}

The readiness to act in new or ambiguous situations in identity-congruent ways is referred to as "action-readiness". If taking a particular action is identitycongruent, "for me" or "for us", that implies the importance of persisting when difficulties starting or staying on course arise. In contrast, if taking a particular action is identity-irrelevant or even identity-incongruent, people are likely to interpret difficulties starting or staying going differently. In these cases, difficulty implies that the action is not for "me" anyway (Elmore \& Oyserman, 2012; Oyserman, 2019b). Prior research has focused on the interplay of social identities with taking school-focused action - studying, engaging in class discussion, paying attention, asking for help, going to the library (e.g., for reviews, Oyserman et al., 2012; Oyserman, 2019b). Though not directly assessed, the implication is that taking identity-congruent action is identity affirming and failing to do so is identity threatening. For example, if good students study, studying should affirm that one is a good student; failing to study implies that one is something else. In the case of the Brexit campaign, social identities, including being British and being an environmentalist, were linked to the particular action of voting "leave". The implication is that if that is what "we" do, a person who fails to vote "leave" might not really be a part of the identity group and worse, might be contributing to the demise of the group and what the group stands for.

As illustrated in Figure 10.1, each of the three identity-based motivation components (dynamic construction of identity, readiness to act, and meaningmaking in identity-congruent ways) operates in tandem. This mutuality means that cues to action not only trigger action but also cascade to meaning-making and identity. Hence, if in context, an identity comes to mind, its implications for meaning-making and action are also afforded. The same holds if an action comes to mind (actions' implications for identity and meaning-making are afforded) or if a way of making sense of experience comes to mind (meaning-making's implications for identity and meaning-making are afforded).

\section{Identity stability is a useful fiction}

Though dynamic construction is a key feature of the functioning of identity-based motivation, people do not necessarily experience their identities or their motivational processes in this flexible way. Instead, people typically experience their identities as stable across time and space (Oyserman, 2019b). This belief is useful for 


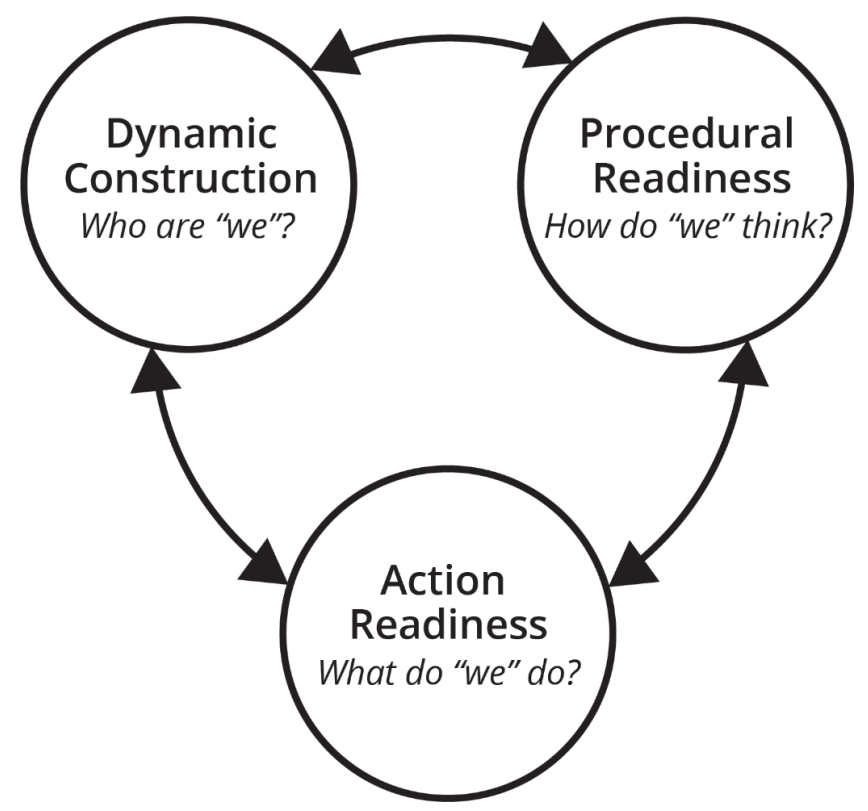

FIGURE 10.1 Three interlocking components

several reasons. First, it allows people to make predictions about their future preferences given what they prefer now by experiencing current "me" and future "me" as essentially the same "me" (Oyserman, 2019b). Second, it facilitates choice among action alternatives. That is, taking current action for the sake of future "me" - doing schoolwork (Nurra \& Oyserman, 2018) or saving for retirement (Lewis \& Oyserman, 2015) - makes sense if current and future "me" are essentially the same. Third, by increasing certainty, it minimizes the extent that people need to seek out supporting information for identity-based choices and sense making.

\section{Consequential yet difficult: shifting from information-based to identity-based reasoning}

Of course, people do not have to use identity-based reasoning; they can (and do) engage in information-based reasoning. Information-based reasoning entails using the information at hand to guide judgment and inform choice. People are likely to use information-based processing when the information to be used is easy to access, clear, and limited; in these cases, computational processing (e.g., trading off risks and rewards) is possible (Reyna, 2004). Information-based reasoning can be quick. For example, which navigation route is faster can be answered by searching a web-based traffic application; which product costs more can be answered by price comparisons. Yet, the information to be used in making choices and forming judgments is often none of these things, particularly 


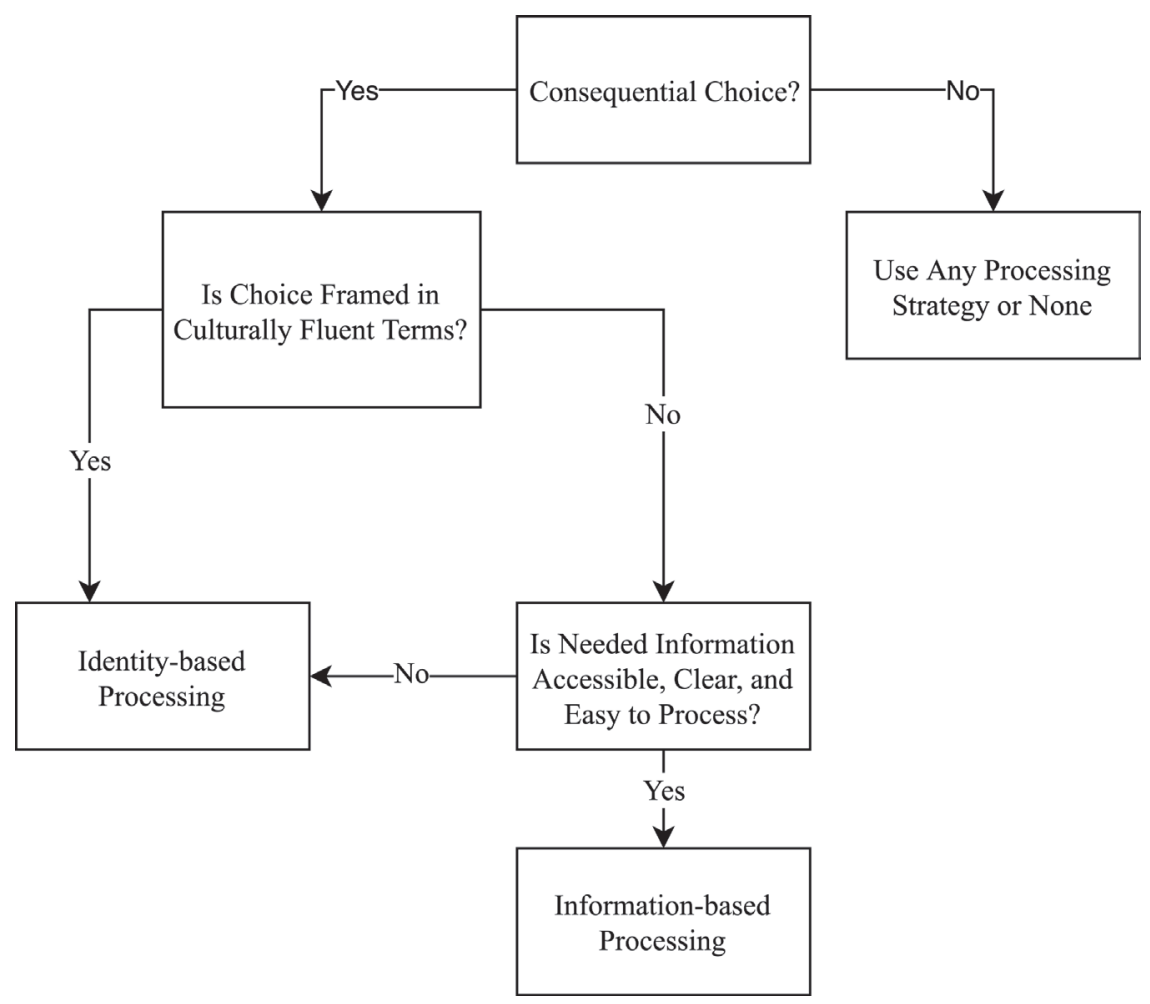

FIGURE 10.2 Cultural fluency as an identity-based processing trigger

when choice is consequential for the long run, but long-run outcomes are complex, uncertain, and difficult to process. Attempting to use a computational rule to process information in these cases is not only difficult, it may not be possible, requiring that people need to use another strategy. We propose that culturally fluent framing of information facilitates a shift from a difficult to address information-based question to an easy to address identity-based one. We summarize this process in Figure 10.2.

\section{Social media and the dissemination of disinformation}

Social media platforms are designed for people to come together and share identity-relevant content. These platforms seem free and friendly - people feel that they are choosing what to engage with, that their choices are not being constrained, and that they can choose whom to affiliate with. Yet by engaging freely in what appears to be a friendly, safe, in-group setting, people also provide platform organizers with a large pool of rich data on themselves and their networks. They, and their data, become a product that platform organizers can sell. This combination - a flow of information through personal "friend" or "follower" connections and the availability of rich data - make social platforms ideal for 
campaigns seeking to spread culturally fluent disinformation messages targeted to important social identities. Users willingly or unwittingly turn over their data and other high-resolution behavioral insights to corporations in exchange for the ability to connect and share information (Redazione, 2018). Much of these data can readily be turned into targeting demographics for advertising. Facebook, for example, generates a vast majority of its revenue from advertising, over $\$ 55$ billion USD in 2018 (Facebook, 2019). Facebook has admitted to allowing Cambridge Analytica to harvest an estimated 87 million Facebook user's information including their networks (Kang \& Frenkel, 2018).

At their core, social media platforms are highly efficient advertising networks. Their algorithms aim to increase content engagement and time spent on the platform by directing attention to stimulating content personalized for an individual, by providing content that fits a user's worldview or content that is emotion-based (Barberá, Jost, Nagler, Tucker, \& Bonneau, 2015; Kramer, Guillory, \& Hancock, 2014). Facebook produces detailed data profiles on users, including facial recognition data, location information, interests, demographics, behaviors, and social network maps; by allowing for interactivity, it can harvest the information people contribute, the specific content users engage with, and what they do with this content (Facebook, n.d.). All of these data can be used to tailor and disseminate disinformation effectively (Facebook, 2019; Shochat, Shniberg, Hirsch, \& Tagiman, 2009). Big data techniques allow abstraction of specific metrics - demographics, psychological abstractions such as personality traits and more - from these data (Kosinski, Stillwell, \& Graepel, 2013).

\section{Identity-based motivation and disinformation campaigns}

We illustrate how this disinformation process works by returning to the example of the Brexit campaign. To succeed, the secession campaign needed to do two things: it needed to persuade some voters to vote "leave" and it needed to persuade other voters to stay home and not vote at all. To do so, the Brexit campaign used targeted disinformation (false or manipulated content meant not to inform but to produce a particular action). The campaign reduced the chances that voters would notice that messages were disinformational by using culturally fluent materials (reducing likelihood of shift to systematic reasoning) and social identities (increase likelihood of collectivistic mental procedures, that is, reasoning in terms of connections and associations). The campaign increased chances that disinformational messages would be accepted by framing judgment and choice in terms of social identities (how "we" think, the choices "we" make), likely triggering both action-readiness and a collectivistic frame (which should increase sensitivity to the communicative intent of the message sender, e.g., Haberstroh, Oyserman, Schwarz, Kühnen, \& Ji, 2002). Having done so, the Brexit campaign then framed a particular action (vote "exit") as the identity-relevant one for some voters. For other voters, the Brexit campaign focused instead on undermining confidence in the triggered identity or in what that identity implied for behavior. This culturally 
fluent identity-based reformulation succeeded in two ways. First, it made Brexit a legitimate question. Second, it freed people from having to digest complex, competing, and uncertain estimates of the financial cost of staying or leaving and allowed them to ask instead what a "stay" or "leave" vote (or voting at all) felt like in terms of who they were. Of course, this reformulation from information-based to identity-based choice could not have worked if people did not already have a preference for making identity-congruent choices, taking identity-congruent action, and making sense of their experiences in identity-congruent ways.

To attain these outcomes, two different secession campaigns, the "BeLeave" campaign and the "Vote Leave" campaign hired a digital firm to run their mediabased persuasion (House of Commons, 2019). The firm, Aggregate IQ (AIQ), is a North American firm whose founders specialize in persuasive power on digital platform-based social media, including Facebook. The firm was an established player in the domain of digital mass persuasion, specifically in the political arena. AIQ developed software products for the SCL group, a large "global election management agency" more commonly known by their subsidiary Cambridge Analytica. AIQ's tools were also used in North American elections by the SCL group, working for the Republican Party (House of Commons, 2018).

To persuade British voters in the Brexit referendum, AIQ used their knowledge of how Facebook operates to generate thousands of different content pieces for Facebook (Facebook, n.d.). The firm took an identity-targeting strategy to disinformation. The chief architect of the information operation framed the underlying thesis as: "We use data to capture and identify a person's identity . . . we design personalized interventions - informational or communications interventions - that will change their behavior in a way that is bespoke to that person" (Cadwalladr, 2018; Redazione, 2018). AIQ both consulted with the campaigns on the efficacy of preexisting content and independently created large quantities of new content. They served this content using internal dissemination teams, leveraging advanced demographic targeting and profiling - that is, they knew who exactly they were targeting with which content pieces, and selected specific pieces for each individual and their personal susceptibilities (House of Commons, 2018). In this way, British citizens were delivered content that looked "right", "rang true", or "spoke" to them, in clear and visceral terms. But what appeared to unsuspecting social media users as simply catchy visuals and tag lines were actually carefully designed culturally fluent frames to deliver an identity-based call to action.

\section{Effects of culturally fluent identity-based motivational framing: the Brexit campaign}

\section{Leveraging culturally fluent identity-based motivation to increase "leave" voting}

Figure 10.3 (teacup) and Figure 10.4 (polar bear) provide two examples of what content pieces meant to propel "leave" voting looked like. The teacup message takes an identity "British" and dynamically constructs particular content from 


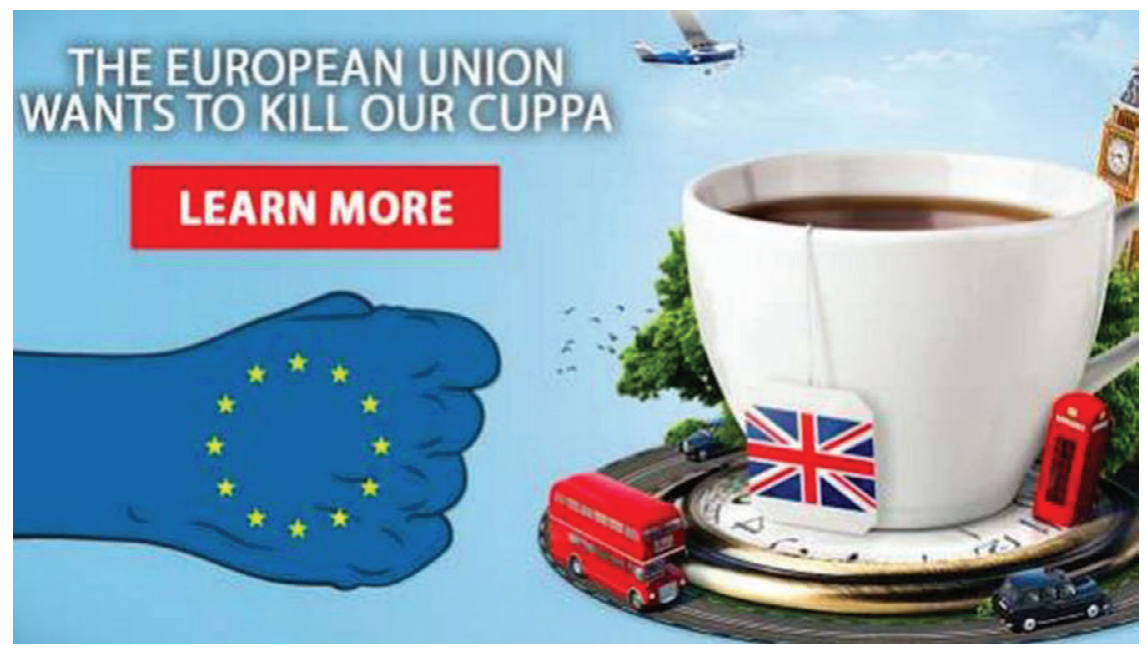

FIGURE 10.3 A culturally fluent nostalgic British identity framing EU secession as necessary for maintenance of British identity

Source: Reprinted from House of Commons under the Open Parliament License v3.0

\section{The EU blocks our ability to speak out and PROTECT polar bears!}

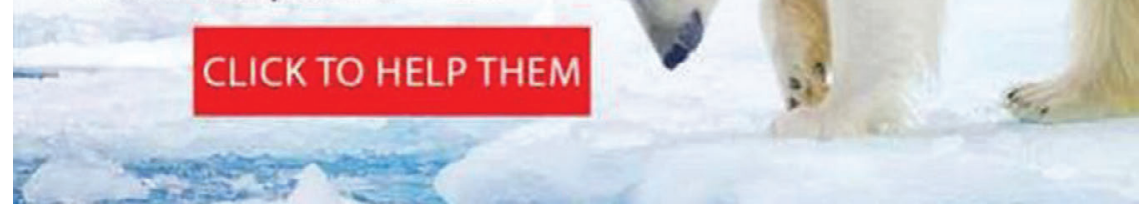

FIGURE 10.4 A culturally fluent environmentalist identity framing EU secession as necessary for maintenance of an environmentalist identity

Source: Reprinted from House of Commons under the Open Parliament License v3.0

this identity. It takes culturally fluent visual (Big Ben, red phone booth) and sensory cues (implied taste of British tea and sound of "cuppa") of "British" and creates a novel meaning that being "British" is best attained by voting the leave the EU. This message is targeted at people for whom Britishness of a certain 
nostalgic nature might easily come to mind and is multifaceted. That is, not only does cuppa informally mean "cup of tea", linguistically cuing Britishness in everyday speech, but the saying "not my cuppa [tea]", means "not for me", adding more cultural fluency. Not only does the teacup message frame a particular course of action for its targeted audience, but it is also so clearly nostalgic that it is unlikely to be experienced as relevant to other audiences. Hence, it is unlikely to mobilize action among a potential "stay" audience.

The polar bear message frames a different identity, environmentalist, and suggests that having that identity requires a specific action - exit the EU. It is targeted at people for whom social identities other than nostalgic Britishness might more easily come to mind. Much like the teacup message, people who are unlikely to have an environmentalist identity triggered are unlikely to process this information as relevant - if anything it might seem just silly. Lacking a framework to make sense of the polar bear, they are unlikely to respond at all to the message.

\section{Leveraging culturally fluent identity-based motivation to undermine "stay" voting}

To persuade potential "stay" voters to just stay home, the Brexit campaign had two options. It could increase doubt that voting "leave" really was a "we" thing to do or increase doubt that voting at all was something that "we" do. Figure 10.5 (jet travel) provides an example of what content pieces meant to undermine certainty that voting was a "me" or "us" thing to do looked like. The jet travel message frames two possible identities, a sensible, frugal British identity

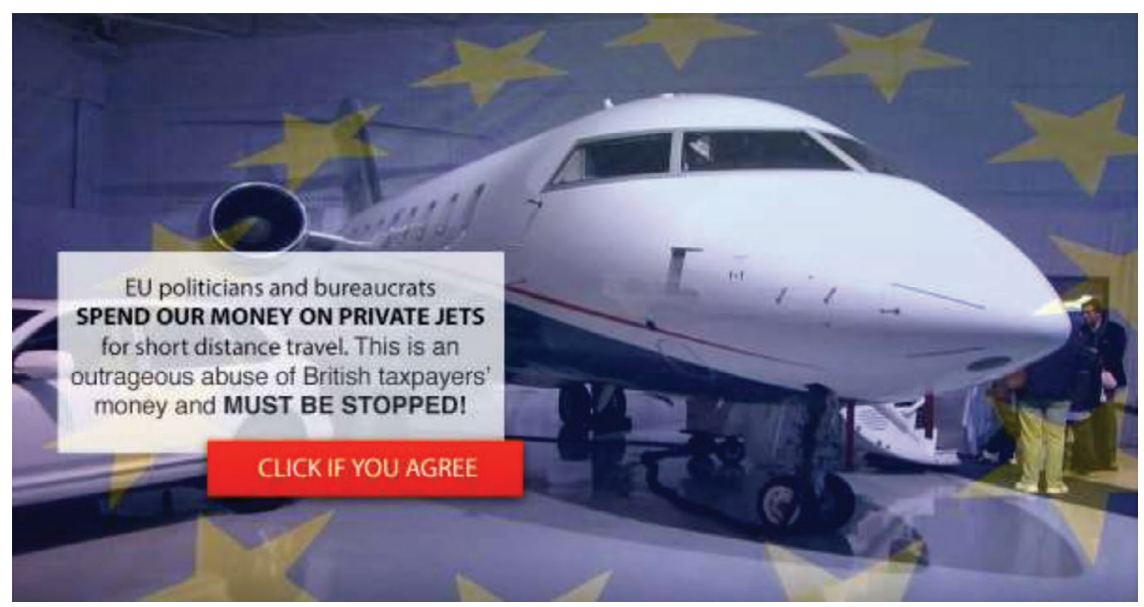

FIGURE 10.5 Culturally fluent framing of EU support as support for corruption resulting in undermined confidence in EU and British identities fitting together Source: Reprinted from House of Commons under the Open Parliament License v3.0 
and an environmental identity. The British identity frame is in some ways similar to the nostalgic teacup frame; in this case, recalling the postwar austerity years. Like the teacup frame, there is no ambiguity to the call for action - vote "exit". In contrast, the environmental identity frame poses the question of whether staying or leaving is the better environmental choice. Like many environmental choices - is it better to wash the recyclable plastic (wasting water) or to throw it into a landfill (wasting energy)? Or is it simpler not to choose? For the environmentalist, the jet travel message undermines certainty as to whether voting "stay" or "leave" is the identity-congruent action. Moreover, with its whiff of potential corruption, the jet travel message undermines certainty that political leaders have anything but their own interests at heart. The message produces a lack of clarity as to which action to take and reduces the likelihood of acting at all. Exposure to this message should reduce the likelihood that environmentalists see voting as clearly identity-congruent while at the same time increasing the likelihood that nostalgic pensioners did. It should undermine certainty that voting at all is identity congruent, given that messages from a corrupt source are unlikely to be providing useful information as to what people like "me" should do.

\section{After the vote: long-term effects}

Because they trigger culturally fluent identity-based reasoning, the effects of disinformation campaigns are likely to be long-lasting. By engaging with culturally fluent social identity-based cues, people are likely to actively produce an identity. This identity triggers immediate action and carries over to frame subsequent judgments. In the case of the Brexit campaign, the immediate action is a shift in voting behavior. Being British is not necessarily antagonistic to being a European, but once framed in this way, people are likely having this association whenever the linked British identity cues come to mind. By linking action to identity-based processing, disinformation triggers, and maintains an associative reasoning style. Because social identities trigger a collectivistic connecting and relating mental procedure, people experience the engineered action as identity-relevant thing to do. It becomes the way "we" act, with the implication that it fits "our" values. As we describe in the section on dynamic construction, disinformation does not need to rely on already available identity-to-action associations. These associations can be constructed in context. However, once they are constructed and repeatedly engaged, whenever the identity is triggered, the associated actions and implied values will be triggered as well (as portrayed in Figure 10.1). Once linked to identity, it is neither necessary nor useful to recall where information came from since disinformation is agnostic as to the veracity of information.

\section{Comparing effectiveness of information, misinformation, and disinformation: a culturally infused IBM perspective}

The conventions of language use lead people to assume that message sharers typically have a goal of informing (Grice's maxims of communication or 'logic 
of communication', Schwarz, 2014). Informing entails sharing content one believes to be factually true, unbiased, and potentially useful for making a decision. This logic holds even if sometimes message sharers get it wrong and, unbeknownst to themselves, misinform by sharing factually untrue or biased content. However, disinformation may be more potent because it focuses directly on shaping judgment and engineering behavior. Hence, misinformation is more likely to affect action. Other informational messaging techniques such as narrative building may effectively change opinion and this may translate the change into action if linked to social identities (Murphy, Frank, Moran, \& Patnoe-Woodley, 2011). That is, rather than change attitudes, narrative techniques may take an identitybased route to persuasion (e.g., via social norms, Paluck, 2009). The implication is that identity-based persuasion techniques can improve an information campaign's likelihood of affecting judgment and behavior, whether or not the information can be accurately recalled. The challenge in correcting misinformation and disinformation is that once a question has been framed as "how do we think about this?", it is unlikely that people will switch to a different question of "what is the probative value of this information?" Worse yet, once people come to believe that "we" think and act in a certain way, they are more unlikely to consider other information as other than "alternative facts". Correction attempts that do not focus on triggering the construction of alternative identity-based reasoning are unlikely to succeed. Future research addressing when identity-based persuasive framing works, when it backfires, and how to address their potential for abuse are sorely needed.

\section{Note}

1 This set of information-based arguments, including job figures, consumer goods prices, and returns on EU investments, was the focus of Britain Stronger in Europe, the leading remain campaign, with the slogan "More Jobs, Lower Prices, and Workers Rights" (www. strongerin.co.uk/).

\section{References}

Barberá, P., Jost, J., Nagler, J., Tucker, J., \& Bonneau, R. (2015). Tweeting from left to right: Is online political communication more than an echo chamber? Psychological Science, 26(10), 1531-1542.

BBC. (2016). Interactive map with regional voter results June 23, 2016. EU Referendum Results. Retrieved September 9, 2019, from www.bbc.com/news/politics/eu_ referendum/results

Blinder, S., \& Markaki, Y. (2018). Public attitudes toward EU mobility and Non-EU immigration: A distinction with little difference (No. WP-18-141). COMPAS, School of Anthropology, University of Oxford. Retrieved September 9, 2019, from www.compas. ox.ac.uk/2015/the-effects-of-immigration-on-nhs-waiting-times/

Boyd, R., \& Richerson, P. J. (2005). The origin and evolution of cultures. New York, NY: Oxford University Press.

Brewer, M. B. (1979). In-group bias in the minimal intergroup situation: A cognitivemotivational analysis. Psychological Bulletin, 86(2), 307-324. 
Britain Stronger in Europe. (n.d.). Britain stronger in Europe. Retrieved September 15, 2019, from www.strongerin.co.uk/get_the_facts. Declared as the official "Remain" campaign for the referendum by the Electoral Commission on 13 April 2016.

Bruner, J. S., \& Postman, L. (1949). On the perception of incongruity: A paradigm. Journal of Personality, 18, 206-223.

Brush, S., \& Weber, A. (2019, July 2). London's fight to remain a financial hub after Brexit. Bloomberg. Retrieved September 9, 2019, from www.bloomberg.com/news/ articles/2019-07-03/london-s-fight-to-remain-a-financial-hub-after-brexit-quicktake

Cadwalladr, C. (2018, March 18). "I made Steve Bannon's psychologicalwarfare tool": Meet the data war whistleblower. The Guardian. Retrieved September 9, 2019, from www.theguardian.com/news/2018/mar/17/data-war-whistleblower-christopherwylie-faceook-nix-bannon-trump

Chiu, C.-Y., Gelfand, M., Harrington, J. R., Leung, A., Liu, Z., Morris, M., . . Z Zou, X. (2015). A conclusion, yet an opening to enriching the normative approach of culture. Journal of Cross-Cultural Psychology, 46(10), 1361-1371.

Chiu, C.-Y., Gelfand, M., Yamagishi, T., Shteynberg, G., \& Wan, C. (2010). Intersubjective culture: The role of intersubjective perceptions in cross-cultural research. Perspectives on Psychological Science, 5(4), 482-493.

Cohen, D. (2001). Cultural variation: Considerations and implications. Psychological Bulletin, 127, 451-471.

Cooper, C. (2016, June 26). Brexit campaigners admit "there is no plan" for what comes next as rivals plan Tory leadership bids. Retrieved September 8, 2019, from www. independent.co.uk/news/uk/politics/brexit-eu-referendum-campaigners-there-isno-plan-next-pm-tory-leadership-contest-a7104711.html

Douthat, R. (2015, May 9). The suicide of Britain. The New York Times. Retrieved September 9, 2019, from www.nytimes.com/2015/05/10/opinion/sunday/ross-douthatthe-suicide-of-britain.html?searchResultPosition $=4$

Elmore, K., \& Oyserman, D. (2012). If "we" can succeed, "I" can too: Identity-based motivation and gender in the classroom. Contemporary Educational Psychology, 37(3), 176-185.

Facebook. (n.d.). Facebook advertising targeting options. Retrieved April 15, 2019, from www.facebook.com/business/ads/ad-targeting\#

Facebook. (2019, January 30). Facebook reports fourth quarter and full year 2018 results. Retrieved April 15, 2019, from https://investor.fb.com/investor-news/press-releasedetails/2019/Facebook-Reports-Fourth-Quarter-and-Full-Year-2018-Results/ default.aspx

Frederick, S. (2005). Cognitive reflection and decision making. Journal of Economic Perspectives, 19(4), 25-42.

Gilbert, D. (1991). How mental systems believe. American Psychologist, 46(2), 107-119.

Gilbert, D., Krull, D., \& Malone, P. (1990). Unbelieving the unbelievable: Some problems in the rejection of false information. Journal of Personality and Social Psychology, 59(4), 601-613.

Giuntella, O., Nicodemo, C., \& Vargas-Silva, C. (2018). The effects of immigration on NHS waiting Times (No. Working Paper No. 124). COMPAS, School of Anthropology, University of Oxford. Retrieved from www.compas.ox.ac.uk/2015/the-effects-ofimmigration-on-nhs-waiting-times/

Goodwin, M. (2015, September 21). Why a "Brexit" looms large. The New York Times. Retrieved September 9, 2019, from www.nytimes.com/2015/09/22/opinion/why-abrexit-looms-large.html?searchResultPosition $=20$

The Guardian. (2016). Interactive map with regional results 06/23/2016. EU Referendum: Full Results and Analysis. Retrieved September 9, 2019, from www.theguardian.com/ 
politics/ng-interactive/2016/jun/23/eu-referendum-live-results-and-analysis? $\mathrm{CMP}=$ twt_b-gdndata

Haberstroh, S., Oyserman, D., Schwarz, N., Kühnen, U., \& Ji, L. J. (2002). Is the interdependent self more sensitive to question context than the independent self? Journal of Experimental Social Psychology, 38(3), 323-329.

Haidle, M., Bolus, M., Collard, M., Conard, N., Garofoli, D., Lombard, M., .. . Whiten, A. (2015). The nature of culture: An eight-grade model for the evolution and expansion of cultural capacities in hominins and other animals. Journal of Anthropological Sciences, 93, 43-70.

House of Commons, Digital, Culture, Media and Sport Committee, United Kingdom. (2018). Disinformation and "fake news": Interim Report: Government Response to the Committee's Fifth Report of Session 2017-19.

House of Commons, Digital, Culture, Media and Sport Committee, United Kingdom. (2019). Disinformation and "fake news": Final Report (Eighth Report of Session 2017-19 ed.).

James, W. (1890). The principles of psychology. New York, NY: Dover.

Kahneman, D., \& Frederick, S. (2002). Representativeness revisited: Attribute substitution in intuitive judgment. In T. Gilovich, D. Griffin, \& D. Kahneman (Eds.), Heuristics and biases: The psychology of intuitive judgment (pp. 49-81). New York, NY: Cambridge University Press.

Kang, C., \& Frenkel, S. (2018, April 4). Facebook says Cambridge Analytica harvested data of up to 87 million users. The New York Times. Retrieved September 9, 2019, from www.nytimes.com/2018/04/04/technology/mark-zuckerberg-testify-congress.html

Kosinski, M., Stillwell, D., \& Graepel, T. (2013). Private traits and attributes are predictable from digital records of human behavior. Proceedings of the National Academy of Sciences, 110(15), 5802-5805.

Kramer, A., Guillory, J., \& Hancock, J. (2014). Experimental evidence of massive-scale emotional contagion through social networks. Proceedings of the National Academy of Sciences, 111(24), 8788-8790.

Kurzban, R., \& Neuberg, S. (2005). Managing ingroup and outgroup relationships. In D. Buss (Ed.), The handbook of evolutionary psychology (pp. 653-675). Hoboken, NJ: John Wiley \& Sons.

Lewis, N., Jr., \& Oyserman, D. (2015). When does the future begin? Time metrics matter, connecting present and future selves. Psychological Science, 26(6), 816-825.

Massie, A. (2015, May 9). Reflections on the revolution in Scotland. The Spectator. Retrieved September 9, 2019, from www.spectator.co.uk/2015/05/this-election-hasbeen-all-about-scotland/

McCrae, R. (2018, July 31). Geographical breakdown of the current account. The Pink Book. Retrieved September 9, 2019, from www.ons.gov.uk/economy/nationalaccounts/ balanceofpayments/datasets/9geographicalbreakdownofthecurrentaccountthepink book 2016

Mourey, J., Lam, B., \& Oyserman, D. (2015). Consequences of cultural fluency. Social Cognition, 33(4), 308-344.

Mourey, J., Oyserman, D., \& Yoon, C. (2013). One without the other: Seeing relationships in everyday objects. Psychological Science, 24(9), 1615-1622.

Murphy, S., Frank, L., Moran, M., \& Patnoe-Woodley, P. (2011). Involved, transported, or emotional? Exploring the determinants of change in knowledge, attitudes, and behavior in entertainment-education. Journal of Communication, 61(3), 407-431.

Nisbett, R., \& Norenzayan, A. (2002). Culture and cognition. In D. Medin (Ed.), Stevens' handbook of experimental psychology (pp. 561-597). New York, NY: Wiley. 
Nurra, C., \& Oyserman, D. (2018). From future self to current action: An identity-based motivation perspective. Self and Identity, 17(3), 343-364.

Oyserman, D. (2007). Social identity and self-regulation. In A. Kruglanski \& E. T. Higgins (Eds.), Social psychology: Handbook of basic principles (pp. 432-453). New York, NY: Guilford Press.

Oyserman, D. (2009). Identity-based motivation: Implications for action-readiness, procedural-readiness, and consumer behavior. Journal of Consumer Psychology, 19, $250-260$.

Oyserman, D. (2011). Culture as situated cognition: Cultural mindsets, cultural fluency, and meaning making. European Review of Social Psychology, 22(1), 164-214.

Oyserman, D. (2015a). Culture as situated cognition. In R. Scott \& S. Kosslyn (Eds.), Emerging trends in the behavioral and social sciences (pp. 1-11). Hoboken, NJ: John Wiley and Sons.

Oyserman, D. (2015b). Pathways to success through identity-based motivation. New York, NY: Oxford University Press.

Oyserman, D. (2017). Culture three ways: Culture and subcultures within countries. Annual Review of Psychology, 68, 435-463.

Oyserman, D. (2019a). Cultural fluency, mindlessness, and gullibility. In R. Baumeister \& J. Forgas (Eds.), The social psychology of gullibility. New York, NY: Routledge.

Oyserman, D. (2019b). The essentialized self: Implications for motivation and selfregulation. Journal of Consumer Psychology, 29(2), 336-343.

Oyserman, D., Elmore, K., \& Smith, G. (2012). Self, self-concept, and identity. In M. Leary \& J. Tangney (Eds.), Handbook of self and identity (pp. 69-104). New York, NY: Guilford Press.

Oyserman, D., Lewis, N., Jr., Yan, V., Fisher, O., O’Donnell, S. C., \& Horowitz, E. (2017). An identity-based motivation framework for self-regulation. Psychological Inquiry, 28, 139-147.

Oyserman, D., Sorensen, N., Reber, R., \& Chen, S. (2009). Connecting and separating mind-sets: Culture as situated cognition. Journal of Personality and Social Psychology, 97(2), 217-235.

Oyserman, D., \& Yan, V. X. (2019). Making meaning: A culture-as-situated cognition approach to the consequences of cultural fluency and disfluency. In S. Kitayama \& D. Cohen (Eds.), Handbook of cultural psychology (pp. 536-565). New York, NY: Guilford Press.

Petty, R., \& Cacioppo, J. T. (1981). Attitudes and persuasion: Classic and contemporary approaches. Dubuque, IA: Wm. C Brown.

Petty, R., \& Cacioppo, J. T. (1984). Source factors and the elaboration likelihood model of persuasion. Advances in Consumer Research, 11, 668-672.

Paluck, E. L. (2009). Reducing intergroup prejudice and conflict using the media: A field experiment in Rwanda. Journal of Personality and Social Psychology, 96(3), 574-587.

Platow, M., Foddy, M., Yamagishi, T., Lim, L., \& Chow, A. (2012). Two experimental tests of trust in in-group strangers: The moderating role of common knowledge of group membership. European Journal of Social Psychology, 42(1), 30-35.

Redazione. (2018, May 9). Exclusive interview with Christopher Wylie, the Cambridge Analytica whistleblower. Vogue Italia. Retrieved September 9, 2019, from www.vogue. it/en/news/daily-news/2018/05/09/interview-with-christopher-wylie-cambridgeanalytica/

Reyna, V. (2004). How people make decisions that involve risk: A dual-processes approach. Current Directions in Psychological Science, 13(2), 60-66. 
Schwarz, N. (2014). Cognition and communication: Judgmental biases, research methods, and the logic of conversation. New York, NY: Psychology Press.

Schwarz, N., Strack, F., Hilton, D., \& Naderer, G. (1991). Base rates, representativeness, and the logic of conversation: The contextual relevance of "irrelevant" information. Social Cognition, 9(1), 67-84.

Schwarz, N., \& Sudman, S. (Eds.). (2012). Context effects in social and psychological research. Berlin and Heidelberg, Germany: Springer Science \& Business Media.

Shochat, E., Shniberg, M., Hirsch, G., \& Tagiman, Y. (2009). U.S. Patent No. US8666198B2. Washington, DC: U.S. Patent \& Trademark Office. Relationship mapping employing multi-dimensional context including facial recognition.

Shteynberg, G. (2015). Shared attention. Perspectives on Psychological Science, 10(5), 579-590.

Shweder, R., \& LeVine, R. (Eds.). (1984). Culture theory: Essays on mind, self and emotion. New York, NY: Cambridge University Press.

Sudman, S., Bradburn, N. M., \& Schwarz, N. (1996). Thinking about answers: The application of cognitive processes to survey methodology. San Francisco, CA: Jossey-Bass.

Triandis, H. (2007). Culture and psychology. In S. Kitayama \& D. Cohen (Eds.), Handbook of cultural psychology (pp. 59-76). New York, NY: Guilford Press.

UK Research and Innovation (2019, August 9) Government pledges to protect science and research post Brexit [Press Release]. Retrieved from www.gov.uk/government/ news/government-pledges-to-protect-science-and-research-post-brexit?utm_ source $=3$ aa9d710-efe1-4eea-b45f-043b81d05c9d

Weedon, J., Nuland, W., \& Stamos, A. (2017). Information operations and Facebook. Retrieved September 9, 2019, from https://fbnewsroomus.files.wordpress.com/2017/04/facebookand-information-operations-v1.pdf 